\title{
Validity of an NGS-based multiple gene panel in identifying actionable mutations for patients with NSCLC in a Chinese hospital
}

\author{
WEI CAO ${ }^{1}$, CHENGHAI YAN $^{2}$, HAILONG WANG $^{2}$, TOM TANG $^{2}$, HAIFENG WANG $^{2}$ and DUJUAN LIU ${ }^{2}$ \\ ${ }^{1}$ Department of Cardiothoracic Surgery, The Second Hospital of Anhui Medical University, Hefei, Anhui 230601; \\ ${ }^{2}$ First Dimension Biosciences (Suzhou) Co., Ltd., Industrial Park, Suzhou, Jiangsu 215126, P.R. China
}

Received February 14, 2018; Accepted March 19, 2019

DOI: $10.3892 / 01.2019 .10265$

\begin{abstract}
Non-small cell lung cancer (NSCLC) is the most common type of lung cancer. A number of targeted therapies have been approved for clinical use or are in clinical trials. Next generation sequencing (NGS) is widely applied in the identification of actionable genomic alterations and enables personalized cancer therapy for patients. Several multiple-gene panels are available in China for the practice of precision medicine-based cancer therapy. However, the efficiency of these panels requires evaluation. The current study investigated 23 NSCLC samples using a custom designed panel of complete coding regions of $\sim 180$ cancer driver genes (FD-180) and whole exome sequencing for control samples, obtained from white blood cell samples. The results obtained suggested that actionable mutations with available targeted therapeutic options were identified in $69.6 \%$ of cases, including $60.9 \%$ of therapeutic targets recommended by the National Comprehensive Cancer Network guidelines. Furthermore, $8.7 \%$ of patients had a gene mutation that potentially qualified them for clinical trials or associated off-label therapies. As such, the results obtained in the current study demonstrated the reliability of the targeted NGS panel and its potential use for identifying actionable gene alterations and designing personalized therapies for patients with NSCLC.
\end{abstract}

\section{Introduction}

In 2015, cancer-associated mortalities in China were estimated at 2.8 million, with 4.3 million newly identified cases, the most common of which being lung cancer (1). Non-small cell lung cancer (NSCLC) is the most commonly histologically diagnosed lung cancer, accounting for $\sim 85-90 \%$ of cases (2). In the past decade, genetic and genomic profiling in NSCLC

Correspondence to: Dr Dujuan Liu, First Dimension Biosciences (Suzhou) Co., Ltd., Industrial Park, 218 Xinghu Street, Suzhou, Jiangsu 215126, P.R. China

E-mail: liudujuan@firstdimension.net

Key words: non-small cell lung cancer, next generation sequencing, tyrosine kinase inhibitors, targeted therapy has improved considerably, and with it, the understanding of underlying molecular mechanisms of disease pathogenesis and strategies for targeted therapies (3-5). Potential inhibition targets for $60 \%$ of NSCLC cases in the form of actionable driver alterations have been identified through molecular profiling (6). Evidence supports the effectiveness of several of these targeted therapies, including, gefitinib [epidermal growth factor receptor (EGFR)-tyrosine kinase inhibitor (TKI)], erlotinib (sensitizing EGFR mutations) and crizotinib [sensitizing ALK receptor tyrosine kinase (ALK) and ROS proto-oncogene 1 receptor tyrosine kinase fusion] (7).

Next-generation sequencing (NGS) is used in the field of genomic research and clinical applications (8). For patients with NSCLC, targeted NGS provides improved drug target screening and additional potential avenues of treatment (9-12). Due to the ever-growing number of discovered predictive markers for therapies and the limited availability of submitted tissue samples, the long-standing 'one test-one drug' paradigm is gradually being replaced by multiplexed genotyping platforms (13). One such platform is the FoundationOne CDx (F1CDx), which received marketing approval by the Food and Drug Administration (FDA). FICDx performs NGS-based in vitro diagnostics to detect genetic mutations in all solid tumor types and serves to identify potential beneficiaries for several FDA-approved targeted treatment options (14). With more NGS platforms being developed, standardization of reports from various test platforms is warranted (15).

In the present study, a total of 23 NSCLC samples, containing 21 Formalin-Fixed Paraffin-Embedded (FFPE) and two cell-free DNA (cf)DNA samples were analyzed. The coding regions of 180 cancer driver genes were explored using The Roche Nimblegen (Roche Nimblegen, Inc.) custom-designed panel. Subsequently, the captured regions were sequenced by NGS to detect various types of mutations. Whenever available (for a total of 16 patients), the sequences were compared with exome sequences obtained from white blood cell (WBC) samples.

\section{Materials and methods}

Specimen collection. A total of 23 patients with stage III/IV NSCLC at the time of diagnosis were included in the present study. Patients were recruited from The Second Hospital of 
Anhui Medical University (Hefei, China) between March 2017 and October 2017. The patients did not receive preoperative chemotherapy or radiotherapy, and those with prior TKI therapy were excluded from the study. There were 21 FFPE specimens and 2 cfDNA specimens in patients who did not have tissue samples available at presentation. All FFPE samples were independently assessed by two experienced pathologists and had a minimum tumor content of $40 \%$. Blood samples from 16 patients were collected as controls to validate the identified germline mutations. Patient clinical data are presented in Table I. The samples were obtained from 10 males and 13 females (median age, 62 years; age range, 31-77 years). Among these patients, there was 1 smoker and 22 non-smokers.

Nucleic acid preparation. Deparaffinization of $40 \mu \mathrm{m}$ tissue sections was performed with $100 \%$ xylene (Sigma Aldrich; Merck KGaA, Darmstadt, Germany) followed by $100 \%$ ethanol as described previously (16). Deparaffinized samples were suspended in proteinase K-contained buffer (Thermo Fisher Scientific, Inc., Waltham, MA, USA). Following extraction using phenol-chloroform (Sigma Aldrich; Merck $\mathrm{KGaA}$ ), DNA samples were treated with ethanol (Sigma Aldrich; Merck $\mathrm{KGaA}$ ) precipitation and resuspended in deionized water. cfDNA blood collection tubes (Streck, Inc., Omaha, NE, USA) were used for the collection of $10 \mathrm{ml}$ blood samples. Procurement of $1.2 \mathrm{ml}$ of plasma from every patient was performed prior to cfDNA extraction using centrifugation twice $\left(4^{\circ} \mathrm{C} ; 1,600 \mathrm{xg}\right.$ for $\left.10 \mathrm{~min}\right)$. cfDNA was isolated with the QIAamp Circulating Nucleic Acid kit (Qiagen, Inc., Valencia, CA, USA) according to the manufacturer's protocol. Validation of adopted protocols for the present study was obtained from previous findings (17). A total of $2 \mathrm{ml}$ of total peripheral blood was used to process WBC DNA as a control, using a FlexiGene DNA kit (Qiagen, Inc.). Quantification of isolated DNA samples was performed using a NanoDrop spectrophotometer (Thermo-Fisher Scientific, Inc.), and by fluorimetry, which was conducted using Qubit dsDNA high-sensitivity and/or broad-range assay kits (Thermo Fisher Scientific, Inc.).

Configuration of the somatic subpanel. The somatic cancer gene list was selected based on the following cancer-associated databases such as the Catalogue of Somatic Mutations in Cancer (COSMIC; cancer.sanger. ac.uk/cosmic), MyCancerGenome (www.mycancergenome. org), CancerIndex (www.cancerindex.org), FDA (www.fda. gov), European Medicines Agency (www.ema.europa.eu/ema), National Comprehensive Cancer Network (NCCN; www.ncen. org), PHARMGKB (www.pharmgkb.org/), MDAnderson Cancer Center (pct.mdanderson.org), DRUGBACK (www. drugbank.ca), ClinicalTrial (clinicaltrials.gov), Google Scholar (scholar.google.com) and PubMed (www.ncbi.nlm. nih.gov/pubmed) databases, studies published between 2000 and 2018.

Configuration of the germline subpanel. A preliminary cancer gene list was built based on germline alterations linked with predisposition for hereditary cancer and sourced from the Human Gene Mutation Database (www.hgmd.cf.ac.uk), ClinVar (www.ncbi.nlm.nih.gov/clinvar), Online Mendelian Inheritance in Man (www.omim.org), Genetics Home Reference (ghr.nlm.
Table I. Overview of patient and tumor characteristics in the present study.

\begin{tabular}{lc}
\hline Characteristics & $\mathrm{n}(\%)$ \\
\hline Sex & \\
Male & $10(43.5)$ \\
Female & $13(54.5)$ \\
Age & \\
$>60$ & $13(54.5)$ \\
$\leq 60$ & $10(43.5)$ \\
Smoking status & \\
Smoker & $1(4.3)$ \\
Non-smoker & $22(95.7)$ \\
Stage & \\
I & $9(39.1)$ \\
II & $1(4.3)$ \\
III & $6(26.1)$ \\
IV & $3(13.0)$ \\
Unknown & $4(17.4)$ \\
Type of specimen & \\
FFPE tissue samples & $21(91.3)$ \\
Cell-free DNA (cfDNA) & $2(8.7)$ \\
Genomic DNA (gDNA) & $16(69.6)$ \\
\hline
\end{tabular}

FFPE, Formalin-fixed, Paraffin-embedded; cfDNA, cell-free DNA; gDNA, genomic DNA.

nih.gov) and Orphanet (www.orpha.net) databases. Filtering of the list was performed and genes were removed based on a number of criteria, including a lack of scientific evidence supporting their association with cancer. The tumor-associated genes in the FD-180 panel were listed in Table II.

Library construction and sequencing. The Whole Exome Sequencing (WES) library was constructed using the Illumina TruSeq DNA Sample Prep kit (Illumina, Inc., San Diego, CA, USA), and targeted exome enrichment was performed using the SeqCap EZ Human Exome Library v2.0 kit (Roche Nimblegen Inc.). Library construction and targeted region enrichment for FD-180 were completed with the KAPA Hyper Prep kit for Illumina platforms (Kapa Biosystems; Roche Diagnostics, Indianapolis, IN, USA) and the SeqCap EZ Choice Library (Roche Nimblegen, Inc.), respectively. The FD-180 panel was used for the simultaneous sequencing of all exons of $\sim 180$ tumor-associated genes (data not shown).

Paired-end sequencing was performed with the Illumina $X$ Ten or NEXT SEQ 500 sequencing instrument (Illumina, Inc.) according to the manufacturer's protocol, yielding $\sim 150$ bp short sequence reads. An average of $\sim 15 \mathrm{G}$ of data was generated for each WES sample, accounting for 100-200X coverage of the entire exome. The average data for FD-180 target samples was 3G.

Data analysis. Raw data were processed into a clean FASTQ output with flexbar (v3.3; https://github.com/seqan/flexbar) 
Table II. The gene list of FD-180 panel.

\begin{tabular}{llllllll}
\hline APC & ATM & \multicolumn{1}{c}{ ATR } & AXIN2 & RECQL4 & RET & RNF43 & RUNX1 \\
\hline BAP1 & BLM & BMPR1A & BRCA1 & SBDS & SDHA & SDHAF2 & SDHB \\
BRCA2 & BRI1 & CDC73 & CDH1 & SDHC & SDHD & SETBP1 & SLC2A2 \\
CDK4 & CDKN1B & CDKN2A & CHEK2 & SLX4 & SMAD4 & SMARCA4 & SMARCB1 \\
CLCN7 & CYLD & DDB2 & DICER1 & SMARCE1 & SPTA1 & STK11 & SUFU \\
EPCAM & ERCC2 & ERCC3 & ERCC4 & TERT & TGFBR2 & TP53 & TP63 \\
ERCC5 & EXT1 & EXT2 & FANCA & TSC1 & TSC2 & VHL & WAS \\
FANCB & FANCC & FANCD2 & FANCE & WRN & WT1 & XPA & XPC \\
FANCF & FANCG & FANCI & FANCL & ABL1 & ABL2 & AKT1 & ALK \\
FANCM & FH & FLCN & GALNT12 & AR & ARAF & ATM & ATR \\
GLA & GPC3 & HNF1A & MAD2L2 & BRAF & BRCA1 & BRCA2 & CDK12 \\
MAX & MEN1 & MLH1 & MLH3 & CDK4 & CDK6 & CRKL & CDKN1A \\
MPL & MSH2 & MSH3 & MSH6 & CDKN2A & CHD4 & CHEK2 & CSF1R \\
MUTYH & NBN & NF1 & NF2 & CTNNB1 & DDR2 & EGFR & ERBB2 \\
PALB2 & PHOX2B & PIK3CA & PMS1 & ERBB3 & ERBB4 & ESR1 & FANCA \\
PMS2 & POLD1 & POLE & PRF1 & FANCB & FANCI & FANCL & FANCC \\
PRKAR1A & PRKCD & PTCH1 & PTEN & FANCD2 & FANCE & FANCF & FANCG \\
RAD50 & RAD51C & RAD51D & RB1 & FANCM & FBXW7 & FGFR1 & FGFR2 \\
TSC1 & TSC2 & XRCC2 & SPOP & FGFR3 & FGFR4 & FRK & FYN \\
MAPK1 & MAPK3 & MET & mTOR & GNA11 & GNAQ & GRM3 & HRAS \\
NF1 & NOTCH1 & NRAS & PDGFRA & IDH1 & IDH2 & KDR & KIT \\
PIK3CA & PIK3CD & PIK3R1 & PTCH1 & KRAS & LYN & MAP2K1 & MAP2K2 \\
PTEN & PTPN11 & RAC1 & RAF1 & RET & ROS1 & SMO & \\
\hline
\end{tabular}

through trimming of adapter sequences and removing reads of insufficient quality (average quality score $<15$ ). Raw reads were checked for the data quality using FASTQC (v0.11.5) (https://www.bioinformatics.babraham.ac.uk/projects/fastqc/). Plots of quality scores across all bases in reads indicated that the majority of positions exhibited a quality score $Q \geq 20$. Raw reads were subsequently trimmed for adapter contamination using Trimmomatic (v0.32; www.usadellab.org). Leading and trailing low-quality bases $(<3)$ were removed. Reads were scanned with a four-base-wide sliding window and the following bases of reads were cut when the average quality per base dropped below 15 . Reads $>50$ bases were selected for subsequent analysis. Paired clean reads following Trimmomatic treatment were aligned against the human genome (hg19) using Burrows-Wheelers Aligner (18). Genome Analysis Toolkit (19) was used to do base quality score recalibration, a process in which machine learning is applied to model quality score errors empirically, and the quality scores are adjusted accordingly. Analysis of the realigned BAM files, and detection of somatic single-nucleotide variants and insertions/deletions was performed using MuTect (20). Normal germline variants were filtered out using the Single Nucleotide Polymorphism Database (dsSNP) (21) or the Exome Aggregation Consortium (ExAC; exac.broadinstitute.org). Default parameter settings were used for all programs. In-house developed scripts were used to eliminate erroneous base calls and generate final mutations based on variant frequency $(>0.5 \%)$. The frequency of variation is equal to the ratio of the depth of the variant allele to the total depth of all alleles at the locus. Remaining variants were annotated using the ExAC and InterPro database (http://www. ebi.ac.uk/interpro/). Gene ontology enrichment was analyzed on the website (www.geneontology.org), focusing on the genes which were mutated in $>4$ primary tumor samples.

\section{Results}

In order to explore the therapeutic relevance of FD-180 and improve the survival rate of patients with NSCLC, 2 cfDNA and 21 FFPE samples were studied to detect driver mutations in tumor DNA with (16 samples) or without matched WBC DNA as a control (mean sequencing depth, 98.96x WES). The average sequencing depth on the 180 target genes for the cfDNA and FFPE samples was $1,747.7 \mathrm{X}$ and $398.4 \mathrm{X}$ respectively. Q30 for all data was $86.4 \%$, where Q scores are defined as a property that is logarithmically associated with the base calling error probabilities. Q30 means that the accuracy of base calling is $99.9 \%(22)$.

Somatic variations in primary tumor. The mutational signature of NSCLC samples was dissected through inspection of the spectrum of base substitutions. All 23 samples exhibited similar point mutation spectra. Cytosine to thymine was the most frequent transversion among somatic mutations, which accounted for $45.6 \%$ in primary tumor tissues (Fig. 1A and B).

Overall, 525 somatic mutations were detected in the 23 NSCLC samples. The primary type of mutation identified was missense mutations (82.1\%; Fig. 1C and D). Notably all the mutations reported were within the protein coding regions, as 
A
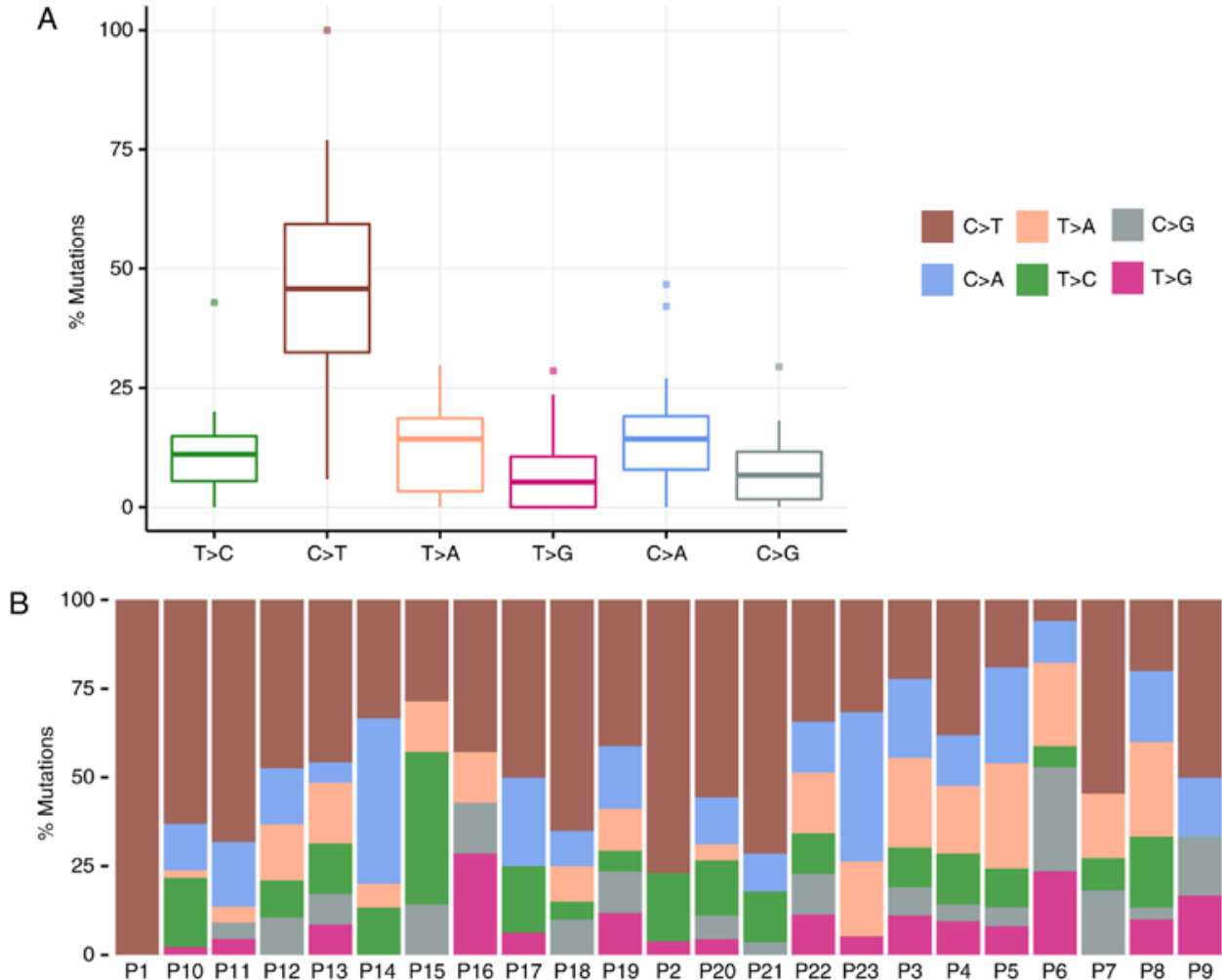

C

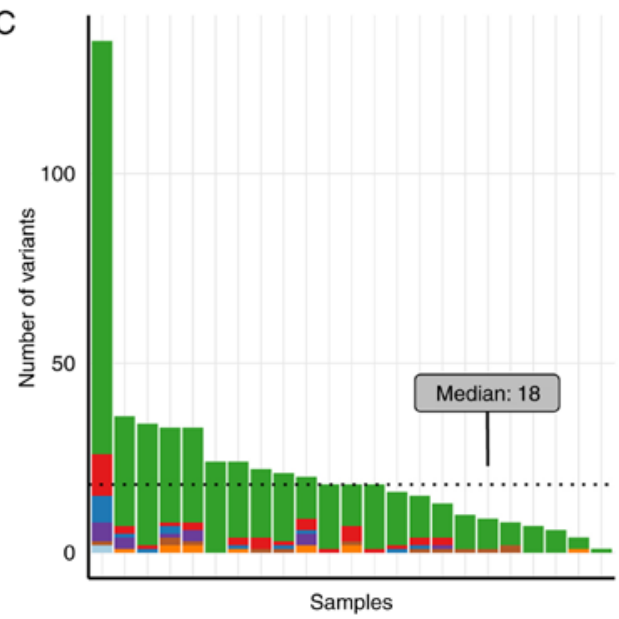

D

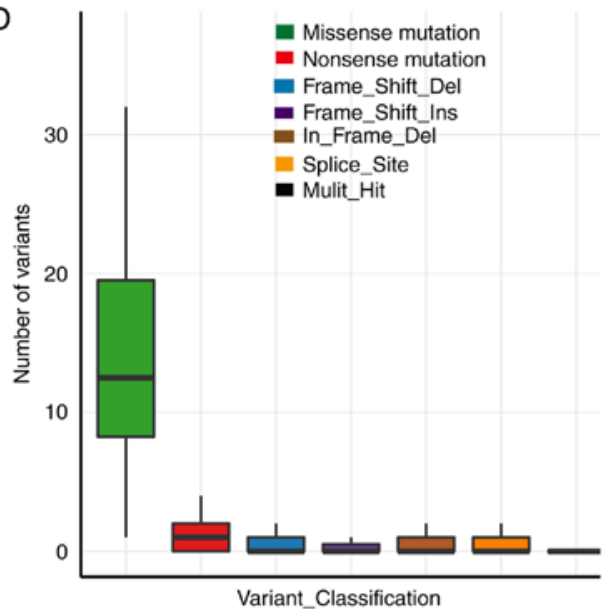

Figure 1. Statistical analyses of somatic mutations in 23 patients with NSCLC. (A) A breakdown of the observed substitution mutations. (B) Distribution of different variation types among all samples. The different colors present the base substitutions in the samples. (C) An overview of the types of mutations observed. (D) Distribution of different variation types among all samples. The different types of mutations are presented using different colors. P1-P23 present the patient ID. T, tyrosine; C, cytosine; A, adenine; G, guanine; Del, deletion; Ins, insertion.

the capturing probes used in the current study were restricted to coding sequences. Variations with $>5 \%$ frequency, as reported in either the dbSNP or the ExAC database, were excluded. Mutation types and numbers were compared with the normal tissue datasets, and the median variant count among the 23 samples was 18 (Fig. 1C and D). The high variant count in patient 1 remains unclear. Possible causes include poor living conditions and long cancer progression time prior to diagnosis.

Implicated biological processes and molecular function. Gene Ontology (www.geneontology.org) enrichment analysis was performed with 40 frequently mutated genes (genes which were mutated in $>4$ primary tumor samples). 'Peptidyl-tyrosine phosphorylation', 'peptidyl-tyrosine modification', 'phosphatidylinositol-mediated signaling', 'inositol lipid-mediated signaling' and 'protein autophosphorylation' were the top five biological process of these high frequency genes in the 23 NSCLC samples (Fig. 2A). Notably, the molecular functions of these genes included 'protein tyrosine kinase activity', 'transmembrane receptor protein tyrosine kinase activity', 'transmembrane receptor protein kinase activity', 'phosphatidylinositol 3-kinase activity' and 'phosphatidylinositol-4,5-bisphosphate-3-kinase activity' (Fig. 2B).

Actionable mutations with available targeted therapies. The top 20 mutated genes in the 23 tumor samples were identified by counting the frequency of mutations in different genes in the 

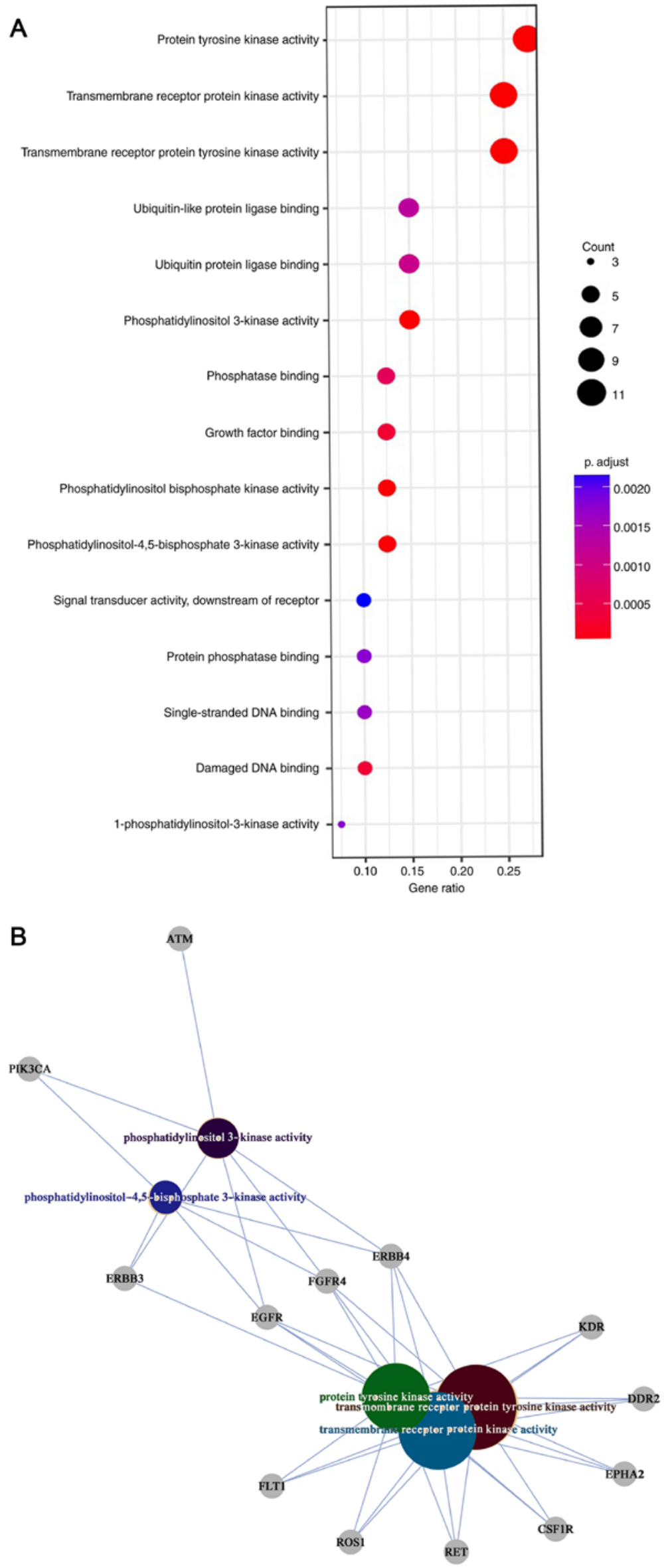

Figure 2. The biological processes and molecular function for the mutational genes in the 23 patients with NSCLC. (A) Main biological processes and gene ratio for frequently mutated genes. (B) Association between frequently mutated genes and their molecular function. Associated genes are present in the grey circles. P adjust, adjusted P-value. NSCLC, non-small cell lung cancer. 


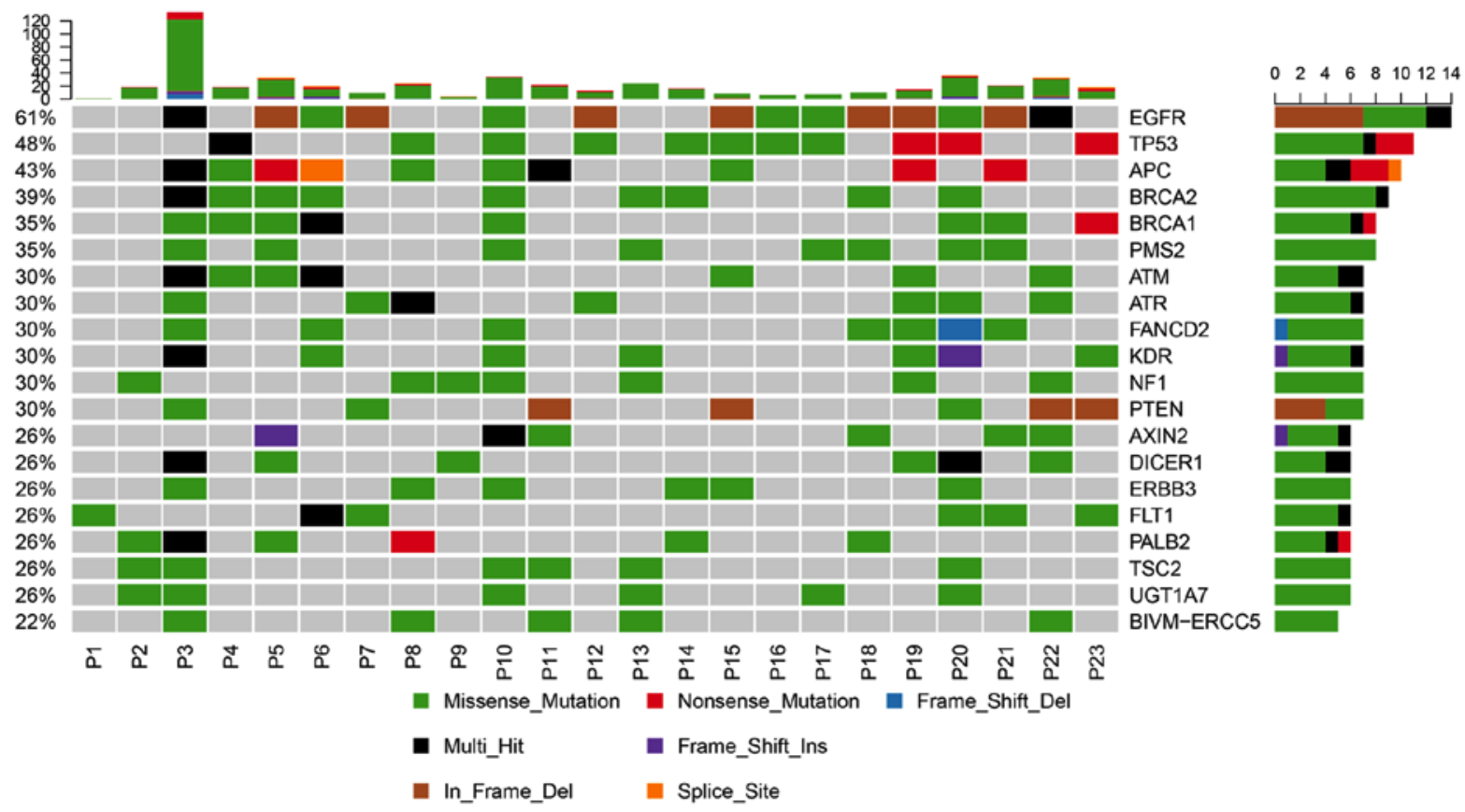

Figure 3. Top 20 mutated genes in the 23 patients with NSCLC. A total of 20 genes' name are listed. P1-P23 present the patient ID. Each type of mutation is presented by a different colour. The values $(0-120)$ on top of the figure present the total number of all the different mutations identified in each patient. The values $(22-61 \%)$ on the left present the frequency of each gene mutation among the 23 patients. The values (0-14) on the right present patient number who harbored the mutations of the listed genes. NSCLC, non-small cell lung cancer.

samples (Fig. 3). EGFR, TP53, and APC were the most conmon mutated gene with a frequency of 61,48 and $43 \%$ respectively. Among the 23 NSCLC samples, 69.57\% (16/23) of the patients carried the mutations with available matched targeted therapeutic options (Table III). This proportion is consistent with the previous study (23). In this study, EGFR mutations which occurred in exon 18-21 were the most common mutations carried by 14 patients. A total of 13 patients harbored the EGFR sensitizing mutations, which were recommended for first-line treatment with gefitinib, erlotinib, afatinib, dacomitinib, Icotinib or osimertinib according to the NCCN, FDA or China Food and Drug Administration (CFDA) guidelines (24-26). One of these 13 patients harbored the acquired resistance mutation EGFR p.T790M, and was amenable to third-generation EGFR inhibitors, including osimertinib, for first-line or subsequent treatment (27). Patient 21 carried EGFR p.746_750del and PIK3CA p.R108H mutations simultaneously (Table III). According to previous studies, approximately 4-5\% of EGFR-mutated lung cancer types with acquired resistance to EGFR-TKI therapy harbor PIK3CA mutations (28-30). A total of 2 patients harbored a KRAS p.G12C mutation, which is a common variant in NSCLC tumors (31). CDKN2A p.W110X was detected simultaneously with EGFR p.E746_A750del in patient 12 (Table III).

Germline mutations with clinical implications. A number of cancer types manifest as a result of inherited defects in key genes within the genome. These genes are a subclass among the cancer driver genes. Their function may involve tumor suppressor genes, oncogenes, genes involved in DNA repair, cell cycle control, apoptosis and angiogenesis factors (32). In the present study, germline mutations were identified through sequencing of the WBC DNA from patients and validated with paired tumor sample sequencing for 16 patients. The cancerous germline mutations identified in the 15 patients are presented in Table IV. A total of 15/16 patients (93.8\%) exhibited cancer driver gene mutations. A total of $57.1 \%$ of the mutations were previously reported in the ExAC database and were described as 'Uncertain significance or not provided' in the NCBI ClinVar database, whereas $42.9 \%$ were identified as de novo mutations.

\section{Discussion}

Several single-institution studies revealed that targeted NGS permits the detection of actionable mutations in clinical lung cancer tumor samples, enabling patient selection for genotype-based therapies (10-12). The present study demonstrated the clinical utility of FD-180 profiling in NSCLC. A total of $69.6 \%$ (16/23) NSCLC samples in the present study were identified to harbor mutations with available matched targeted therapeutic options. Notably, 13 patients harbored actionable EGFR mutations, with treatment recommended. However, 3 patients may benefit from drug agents, which have not yet been approved for lung cancer. The available data indicating PIK3CA mutations that predict the response of solid tumors to phosphoinositide 3-kinase (PI3K) signaling pathway inhibitors, including everolimus (33) and temsirolimus $(34,35)$, remain controversial. Multiple PI3K inhibitors, including BYL719, buparlisib (BKM120), taselisib (GDC0032), and GSK2636771, are under investigation in patients with PIK3CA-mutated or PTEN-mutated solid tumors (36).

KRAS p.G12C has been negatively associated with progression-free survival (37) and decreased sensitivity of EGFR-TKIs, including erlotinib and gefitinib $(38,39)$. Currently, the role KRAS mutations serve in the selection of anticancer treatment remains unclear; however, clinical evidence suggests 
Table III. Actionable genomic alterations and implications for targeted therapeutics.

\begin{tabular}{|c|c|c|c|c|}
\hline $\begin{array}{l}\text { Patient } \\
\text { ID }\end{array}$ & Genomic alterations & $\begin{array}{l}\text { Allele frequency } \\
\text { in current study }\end{array}$ & Associated drugs & $\begin{array}{l}\text { Implication for targeted } \\
\text { therapeutics }\end{array}$ \\
\hline P3 & EGFR p.747_753del & 0.249 & $\begin{array}{l}\text { Gefitinib, Erlotinib, Afatinib, } \\
\text { Icotinib, Osimertinib }\end{array}$ & EGFR-TKI sensitive \\
\hline P5 & EGFR p.746_750del & 0.205 & $\begin{array}{l}\text { Gefitinib, Erlotinib, Afatinib, } \\
\text { Icotinib, Osimertinib }\end{array}$ & EGFR-TKI sensitive \\
\hline P6 & EGFR p.L858R & 0.382 & $\begin{array}{l}\text { Gefitinib, Erlotinib, Afatinib, } \\
\text { Icotinib, Osimertinib }\end{array}$ & EGFR-TKI sensitive \\
\hline P7 & EGFR p.745_750del & 0.378 & $\begin{array}{l}\text { Gefitinib, Erlotinib, Afatinib, } \\
\text { Icotinib, Osimertinib }\end{array}$ & EGFR-TKI sensitive \\
\hline \multirow[t]{2}{*}{ P8 } & KRAS p.G12C & 0.156 & $\begin{array}{l}\text { Trametinib, Everolimus, } \\
\text { Temsirolimus }\end{array}$ & Possibly sensitive \\
\hline & & & $\begin{array}{l}\text { Gefitinib, Erlotinib, Afatinib, } \\
\text { Icotinib }\end{array}$ & $\begin{array}{l}\text { Decreased EGFR-TKI } \\
\text { sensitivity }\end{array}$ \\
\hline \multirow[t]{2}{*}{ P10 } & EGFR p.L861Q & 0.206 & $\begin{array}{l}\text { Gefitinib, Erlotinib, Afatinib, } \\
\text { Icotinib, Osimertinib }\end{array}$ & EGFR-TKI sensitive \\
\hline & EGFR p.G719C & 0.252 & $\begin{array}{l}\text { Gefitinib, Erlotinib, Afatinib, } \\
\text { Icotinib, Osimertinib }\end{array}$ & EGFR-TKI sensitive \\
\hline \multirow[t]{2}{*}{ P12 } & CDKN2A p.W110X & 0.246 & Palbociclib & Possibly sensitive \\
\hline & EGFR p.E746_A750del & 0.102 & $\begin{array}{l}\text { Gefitinib, Erlotinib, Afatinib, } \\
\text { Icotinib, Osimertinib }\end{array}$ & EGFR-TKI sensitive \\
\hline P15 & EGFR p.746_750del & 0.248 & $\begin{array}{l}\text { Gefitinib, Erlotinib, Afatinib, } \\
\text { Icotinib, Osimertinib }\end{array}$ & EGFR-TKI sensitive \\
\hline P16 & EGFR p.L858R & 0.297 & $\begin{array}{l}\text { Gefitinib, Erlotinib, Afatinib, } \\
\text { Icotinib, Osimertinib }\end{array}$ & EGFR-TKI sensitive \\
\hline P17 & EGFR p.L858R & 0.287 & $\begin{array}{l}\text { Gefitinib, Erlotinib, Afatinib, } \\
\text { Icotinib, Osimertinib }\end{array}$ & EGFR-TKI sensitive \\
\hline $\mathrm{P} 18$ & EGFR p.747_752del & 0.14 & $\begin{array}{l}\text { Gefitinib, Erlotinib, Afatinib, } \\
\text { Icotinib, Osimertinib }\end{array}$ & EGFR-TKI sensitive \\
\hline P19 & EGFR p.E746_A750del & 0.367 & $\begin{array}{l}\text { Gefitinib, Erlotinib, Afatinib, } \\
\text { Icotinib, Osimertinib }\end{array}$ & EGFR-TKI sensitive \\
\hline $\mathrm{P} 20$ & EGFR p.L858R & 0.139 & $\begin{array}{l}\text { Gefitinib, Erlotinib, Afatinib, } \\
\text { Icotinib, Osimertinib }\end{array}$ & EGFR-TKI sensitive \\
\hline \multirow[t]{2}{*}{$\mathrm{P} 21$} & EGFR p.746_750del & 0.367 & $\begin{array}{l}\text { Gefitinib, Erlotinib, Afatinib, } \\
\text { Icotinib, Osimertinib }\end{array}$ & $\begin{array}{l}\text { Decreased EGFR-TKI } \\
\text { sensitivity }\end{array}$ \\
\hline & PIK3CA p.R108H & 0.061 & Everolimus, Temsirolimus & Possibly sensitive \\
\hline \multirow[t]{2}{*}{$\mathrm{P} 22$} & EGFR p.L747_T751del & 0.157 & $\begin{array}{l}\text { Gefitinib, Erlotinib, Afatinib, } \\
\text { Icotinib, Osimertinib }\end{array}$ & EGFR-TKI sensitive \\
\hline & EGFR p.T790M & 0.208 & Osimertinib & EGFR-TKI sensitive \\
\hline \multirow[t]{2}{*}{$\mathrm{P} 23$} & KRAS p.G12C & 0.464 & $\begin{array}{l}\text { Trametinib, Everolimus, } \\
\text { Temsirolimus }\end{array}$ & Possibly sensitive \\
\hline & & & $\begin{array}{l}\text { Gefitinib, Erlotinib, Afatinib, } \\
\text { Icotinib }\end{array}$ & $\begin{array}{l}\text { Decreased EGFR-TKI } \\
\text { sensitivity }\end{array}$ \\
\hline
\end{tabular}

EGFR, epidermal growth factor receptor; TKI, tyrosine kinase inhibitor; KRAS, KRAS proto-oncogene, GTPase.

that KRAS-mutant tumors, specifically in lung adenocarcinoma, respond positively to selumetinib and trametinib (40). A phase II randomized trial indicated that a selumetinib and docetaxel combined therapy increased overall response rates and progression free survival in patients with KRAS-mutant NSCLC compared with the placebo control group (41).
A mouse model indicated that serine/threonine kinase 11-deficient KRAS mutant NSCLC tumors were resistant to mitogen-activated protein kinase (MEK) inhibition, which may be clinically relevant $(42,43)$. In a phase I dose escalation trial with the MEK inhibitor trametinib, reductions in tumor size of $6-52 \%$ were observed in $8 / 22$ patients with KRAS 
Table IV. Germline mutations in cancer susceptibility genes in 15 patients.

\begin{tabular}{|c|c|c|c|c|c|c|}
\hline $\begin{array}{l}\text { Patient } \\
\text { ID }\end{array}$ & Gene & $\begin{array}{l}\text { Amino acid } \\
\text { change }\end{array}$ & InterPro domain & $\begin{array}{l}\text { Reference single } \\
\text { nucleotide } \\
\text { polymorphism } \\
\text { ID number }\end{array}$ & $\begin{array}{l}\text { Allele frequency } \\
\text { in the Exome } \\
\text { Aggregation } \\
\text { Consortium }\end{array}$ & $\begin{array}{l}\text { Allele } \\
\text { frequency in } \\
\text { current study }\end{array}$ \\
\hline \multirow[t]{2}{*}{$\mathrm{P} 1$} & FANCD2 & p.D662V & - & - & - & 0.37 \\
\hline & SLX4 & p.D1425N & - & rs766448056 & $9.05 \times 10^{-06}$ & 0.58 \\
\hline \multirow[t]{2}{*}{ P11 } & POLE & p.F2258L & - & - & - & 0.51 \\
\hline & TSC2 & p.P1158S & - & - & - & 0.47 \\
\hline $\mathrm{P} 14$ & FANCM & p.H1103P & - & rs191339110 & $8.28 \times 10^{-06}$ & 0.39 \\
\hline \multirow[t]{2}{*}{$\mathrm{P} 15$} & PTCH1 & p.T265S & - & rs201174718 & 0.0001 & 0.51 \\
\hline & WRN & p.K577T & $\begin{array}{l}\text { DEAD/DEAH box helicase } \\
\text { domain; Helicase superfamily } \\
\text { 1/2 ATP-binding domain; } \\
\text { P-loop containing nucleoside } \\
\text { triphosphate hydrolase }\end{array}$ & - & - & 0.49 \\
\hline P16 & EXT1 & p.V356L & - & - & - & 0.47 \\
\hline \multirow[t]{3}{*}{ P19 } & ATM & p.A1315V & Armadillo-type fold & - & - & 0.55 \\
\hline & AXIN2 & p.V619A & - & - & - & 0.45 \\
\hline & FANCA & p.D694N & - & rs201589909 & 0.0001 & 0.40 \\
\hline \multirow[t]{2}{*}{ P22 } & FANCG & p.P590A & - & rs541868979 & $9.07 \times 10^{-05}$ & 0.33 \\
\hline & PMS1 & p.R202K & $\begin{array}{l}\text { Histidine kinase like ATPase } \\
\text { C-terminal domain; Ribosomal } \\
\text { protein S5 domain 2-type fold; } \\
\text { Ribosomal protein S5 domain } \\
\text { 2-type fold subgroup }\end{array}$ & rs2066459 & 0.012 & 0.58 \\
\hline $\mathrm{P} 23$ & MSH3 & p.R574Q & $\begin{array}{l}\text { DNA mismatch repair protein } \\
\text { MutS core }\end{array}$ & rs776668872 & $8.72 \times 10^{-06}$ & 0.46 \\
\hline \multirow[t]{4}{*}{ P3 } & CLCN7 & p.N104K & Chloride channel core & - & - & 0.58 \\
\hline & MLH3 & p.V741F & - & rs28756990 & 0.0145 & 0.44 \\
\hline & PTEN & c.-326_-324del & - & - & - & 0.18 \\
\hline & SPTA1 & p.N2057S & - & rs761106571 & $5.80 \times 10^{-05}$ & 0.46 \\
\hline P4 & FANCM & p.I552T & $\begin{array}{l}\text { Helicase C-terminal; P-loop } \\
\text { containing nucleoside triphos } \\
\text { phate hydrolase }\end{array}$ & rs200240871 & $8.25 \times 10^{-06}$ & 0.58 \\
\hline P5 & BLM & p.R1139Q & $\begin{array}{l}\text { RQC domain; Winged helix turn } \\
\text { helix DNA binding domain }\end{array}$ & rs771776126 & $8.24 \times 10^{-06}$ & 0.5 \\
\hline P6 & STK11 & p.P411L & - & - & - & 0.65 \\
\hline \multirow[t]{4}{*}{ P7 } & APC & p.A1753P & - & rs587781350 & $1.66 \times 10^{-05}$ & 0.49 \\
\hline & ATM & p.D841Y & - & - & - & 0.41 \\
\hline & FANCA & p.T1161K & - & rs 142833057 & $3.30 \times 10^{-05}$ & 0.55 \\
\hline & SPTA1 & p.D607H & - & rs534906145 & $8.28 \times 10^{-06}$ & 0.58 \\
\hline P8 & POLD1 & p.R322H & $\begin{array}{l}\text { DNA-directed DNA poly } \\
\text { merase family B exonuclease } \\
\text { domain; Ribonuclease H like } \\
\text { domain }\end{array}$ & - & - & 0.39 \\
\hline \multirow[t]{2}{*}{ P9 } & CLCN7 & p.R775H & CBS domain & rs534953229 & 0.0002 & 0.33 \\
\hline & SLC2A2 & p.G519E & - & rs 147959014 & 0.0018 & 0.39 \\
\hline
\end{tabular}

-, information not available.

mutation-positive tumors (44). However, the aforementioned studies require further validation with larger sample sizes and inclusion of KRAS wild-type tumors for comparison to enhance the evidence for clinical efficacy. Therefore, the use of MEK inhibitors for treating KRAS mutation-positive tumors is only recommended in a clinical trial setting. 
Somatic mutations of CDKN2A are present in various tumor types (45-47). However, currently there are no existing standard therapy options to treat tumors harboring somatic CDKN2A alterations. The loss of function mutation of CDKN2A leads to activation of CDK2/4/6, suggesting that CDK inhibitors may be beneficial for these patients (48). Palbociclib is a highly selective CDK4/6 inhibitor, which has demonstrated sensitivity in in vitro studies of renal cell carcinoma (49), melanoma (50), ovarian cancer (51) and breast cancer (52) cell lines, suggesting that this drug may be effective for the treatment of patients included in the present study.

Even though actionable genomic alterations are primarily somatically acquired, it has been reported that inherited cancer predisposition is predominantly associated with germline mutations (32). In this study a total of $93.8 \%$ of patients $(15 / 16)$ carried germline mutations which have been previously associated with cancer. Among these 28 mutations, known and de novo germline mutations were identified in $57.1 \%(16 / 28)$ and $42.9 \%(12 / 28)$, respectively. Only a small proportion of NSCLC cases may be attributed to inheritance of genetic mutations (53). However, the results obtained in the present study suggested otherwise, indicating that the association between the identified mutations and lung cancer requires further investigation with a larger sample size.

Notably, the current study does not provide information on the long-term impact of the FD-180 gene panel on treatment outcomes, including morbidity, quality of life, disease-free survival and overall mortality. A limitation of the present study is therefore the lack of long-term follow-up to monitor these parameters. In conclusion, the present study demonstrated that the FD-180 gene panel is a robust diagnostic tool which may be used to identify targeted therapeutics for patients with NSCLC.

\section{Acknowledgements}

The authors would like to thank Mr. Paul Ma [First Dimension Biosciences (Suzhou) Co., Ltd.,] for his contributions in revising this manuscript.

\section{Funding}

The present study was partly funded by First Dimension BioSciences (Suzhou), Co., Ltd.

\section{Availability of data and material}

The raw sequencing data are not publicly available due to information that could compromise the privacy of the research participants.

\section{Authors' contributions}

WC and TT designed the study. HFW collected the data. CY and HLW analyzed the data. DL designed and wrote the manuscript. All authors have read and approved the final manuscript.

\section{Ethics approval and consent to participate}

The Anhui Medical University Ethics Committee approved the study and all patients have given written informed consent prior to inclusion in the project.

\section{Patient consent for publication}

All patients provided a comprehensive consent form stating that personal data may be used for academic presentation or paper presentation, while ensuring complete anonymity prior to receiving treatment.

\section{Competing interests}

The authors declare that they have no competing interests.

\section{References}

1. Chen W, Zheng R, Baade PD, Zhang S, Zeng H, Bray F, Jemal A, $\mathrm{Yu}$ XQ and He J: Cancer statistics in China, 2015. CA Cancer J Clin 66: 115-132, 2016.

2. Li SD, Ma M, Li H, Waluszko A, Sidorenko T, Schadt EE, Zhang DY, Chen R and Ye F: Cancer gene profiling in non-small cell lung cancers reveals activating mutations in JAK 2 and JAK3 with therapeutic implications. Genome Med 9: 89, 2017.

3. Díaz-Serrano A, Gella P, Jiménez E, Zugazagoitia J and Paz-Ares Rodríguez L: Targeting egfr in lung cancer: Current standards and developments. Drugs 78: 893-911, 2018.

4. Ritter DI, Roychowdhury S, Roy A, Rao S, Landrum MJ, Sonkin D, Shekar M, Davis CF, Hart RK, Micheel C, et al: Somatic cancer variant curation and harmonization through consensus minimum variant level data. Genome Med 8: 117, 2016.

5. Hensing T, Chawla A, Batra R and Salgia R: A personalized treatment for lung cancer: Molecular pathways, targeted therapies, and genomic characterization. Adv Exp Med Biol 799: 85-117, 2014.

6. Vendrell JA, Taviaux S, Béganton B, Godreuil S, Audran P, Grand D, Clermont E, Serre I, Szablewski V, Coopman P, et al: Detection of known and novel ALK fusion transcripts in lung cancer patients using next-generation sequencing approaches. Sci Rep 7: 12510, 2017.

7. Saarenheimo J, Eigeliene N, Andersen H, Tiirola M and Jekunen A: The value of liquid biopsies for guiding therapy decisions in non-small cell lung cancer. Front Oncol 9: 129, 2019.

8. Cheng Y, Wang S, Han L, Liu P, Li H, Ren X, Yu J and Hao X: Concurrent somatic mutations in driver genes were significantly correlated with lymph node metastasis and pathological types in solid tumors. Oncotarget 8: 68746-68757, 2017.

9. Ke EE and Wu YL: Afatinib in the first-line treatment of epidermal-g rowth-factor-receptor mutation-positive non-small cell lung cancer: A review of the clinical evidence. Ther Adv Respir Dis 10: 256-264, 2016.

10. Wang S, Cang S and Liu D: Third-generation inhibitors targeting EGFR T790M mutation in advanced non-small cell lung cancer. J Hematol Oncol 9: 34, 2016.

11. Zhang YC, Zhou Q and Wu YL: Efficacy of crizotinib in first-line treatment of adults with ALK-positive advanced NSCLC. Expert Opin Pharmacother 17: 1693-1701, 2016.

12. Gainor JF and Shaw AT: Novel targets in non-small cell lung cancer: ROS1 and RET fusions. Oncologist 18: 865-875, 2013.

13. Illei PB, Belchis D, Tseng LH, Nguyen D, De Marchi F, Haley L, Riel S, Beierl K, Zheng G, Brahmer JR, et al: Clinical mutational profiling of 1006 lung cancers by next generation sequencing. Oncotarget 8: 96684-96696, 2017.

14. Allegretti M,Fabi A, Buglioni S, Martayan A,Conti L, Pescarmona E, Ciliberto $\mathrm{G}$ and Giacomini P: Tearing down the walls: FDA approves next generation sequencing (NGS) assays for actionable cancer genomic aberrations. J Exp Clin Cancer Res 37: 47, 2018.

15. Zhang YC,Zhou Q and Wu YL: The emerging roles of NGS-based liquid biopsy in non-small cell lung cancer. J Hematol Oncol 10: 167, 2017.

16. Miranda E, Destro A, Malesci A, Balladore E, Bianchi P, Baryshnikova E, Franchi G, Morenghi E, Laghi L, Gennari L and Roncalli M: Genetic and epigenetic changes in primary metastatic and nonmetastatic colorectal cancer. Br J Cancer 95: 1101-1107, 2006.

17. Malapelle U, Mayo de-Las-Casas C, Rocco D, Garzon M, Pisapia P, Jordana-Ariza N, Russo M, Sgariglia R, De Luca C, Pepe F, et al: Development of a gene panel for next-generation sequencing of clinically relevant mutations in cell-free DNA from cancer patients. Br J Cancer 116: 802-810, 2017.

18. Li H and Durbin R: Fast and accurate short read alignment with Burrows-Wheeler transform. Bioinformatics 25: 1754-1760, 2009. 
19. McKenna A, Hanna M, Banks E, Sivachenko A, Cibulskis K Kernytsky A, Garimella K, Altshuler D, Gabriel S, Daly M and DePristo MA: The genome analysis toolkit: A MapReduce framework for analyzing next-generation DNA sequencing data. Genome Res 20: 1297-1303, 2010.

20. Cibulskis K, Lawrence MS, Carter SL, Sivachenko A, Jaffe D, Sougnez C, Gabriel S, Meyerson M, Lander ES and Getz G: Sensitive detection of somatic point mutations in impure and heterogeneous cancer samples. Nat Biotechnol 31: 213-219, 2013.

21. Sherry ST, Ward MH, Kholodov M, Baker J, Phan L, Smigielski EM and Sirotkin K: dbSNP: The NCBI database of genetic variation. Nucleic Acids Res 29: 308-311, 2001

22. Tassios PT and Moran-Gilad J: Bacterial next generation sequencing (NGS) made easy. Clin Microbiol Infect 24: 332-334, 2018.

23. Cabanillas R, Diñeiro M, Castillo D, Pruneda PC, Penas C, Cifuentes GA, de Vicente Á, Durán NS, Álvarez R, Ordóñez GR and Cadiñanos J: A novel molecular diagnostics platform for somatic and germline precision oncology. Mol Genet Genomic Med 5: 336-359, 2017

24. Forde PM and Ettinger DS: Managing acquired resistance in EGFR-mutated non-small cell lung cancer. Clin Adv Hematol Oncol 13: 528-532, 2015.

25. Zhao D, Chen X, Qin N, Su D, Zhou L, Zhang Q, Li X, Zhang X, Jin $M$ and Wang J: The prognostic role of EGFR-TKIs for patients with advanced non-small cell lung cancer. Sci Rep 7: 40374, 2017

26. Kucharczuk CR, Ganetsky A and Vozniak JM: Drug-drug interactions, safety, and pharmacokinetics of EGFR tyrosine kinase inhibitors for the treatment of non-small cell lung cancer. J Adv Pract Oncol 9: 189-200, 2018

27. Ramalingam SS, Yang JC, Lee CK, Kurata T, Kim DW, John T, Nogami N, Ohe Y, Mann H, Rukazenkov Y, et al: Osimertinib as first-line treatment of EGFR mutation-positive advanced non-small-cell lung cancer. J Clin Oncol 36: 841-849, 2018

28. SequistLV, Waltman BA, Dias-Santagata D, Digumarthy S, Turke AB, Fidias P, Bergethon K, Shaw AT, Gettinger S, Cosper AK, et al: Genotypic and histological evolution of lung cancers acquiring resistance to EGFR inhibitors. Sci Transl Med 3: 75ra26, 2011.

29. Ludovini V, Bianconi F, Pistola L, Chiari R, Minotti V, Colella R, Giuffrida D, Tofanetti FR, Siggillino A, Flacco A, et al: Phosphoinositide-3-kinase catalytic alpha and KRAS mutations are important predictors of resistance to therapy with epidermal growth factor receptor tyrosine kinase inhibitors in patients with advanced non-small cell lung cancer. J Thorac Oncol 6: 707-715, 2011

30. Li S, Li L, Zhu Y, Huang C, Qin Y, Liu H, Ren-Heidenreich L, Shi B, Ren H, Chu X, et al: Coexistence of EGFR with KRAS, or BRAF, or PIK3CA somatic mutations in lung cancer: a comprehensive mutation profiling from 5125 Chinese cohorts. $\mathrm{Br}$ J Cancer 110: 2812-2820, 2014.

31. Brose MS, Volpe P, Feldman M, Kumar M, Rishi I, Gerrero R, Einhorn E, Herlyn M, Minna J, Nicholson A, et al: BRAF and RAS mutations in human lung cancer and melanoma. Cancer Res 62: 6997-7000, 2002

32. Cheng DT, Prasad M, Chekaluk Y, Benayed R, Sadowska J, Zehir A, Syed A, Wang YE, Somar J, Li Y, et al: Comprehensive detection of germline variants by MSK-IMPACT, a clinical diagnostic platform for solid tumor molecular oncology and concurren cancer predisposition testing. BMC Med Genomics 10: 33, 2017.

33. Wheler JJ, Moulder SL, Naing A, Janku F, Piha-Paul SA Falchook GS, Zinner R, Tsimberidou AM, Fu S, Hong DS, et al: Anastrozole and everolimus in advanced gynecologic and breast malignancies: Activity and molecular alterations in the PI3K/AKT/mTOR pathway. Oncotarget 5: 3029-3038, 2014.

34. Moroney J, Fu S, Moulder S, Falchook G, Helgason T, Levenback C, Hong D, Naing A, Wheler J and Kurzrock R: Phase I study of the antiangiogenic antibody bevacizumab and the mTOR/hypoxia-inducible factor inhibitor temsirolimus combined with liposomal doxorubicin: Tolerance and biological activity. Clin Cancer Res 18: 5796-5805, 2012.

35. Mackay HJ, Eisenhauer EA, Kamel-Reid S, Tsao M, Clarke B, Karakasis K, Werner HM, Trovik J, Akslen LA, Salvesen HB, et al: Molecular determinants of outcome with mammalian target of rapamycin inhibition in endometrial cancer. Cancer 120: 603-610, 2014

36. Lovly C, Horn L, Pao W: PIK3CA c.1633G >A (E545K) mutation in non-small cell lung cancer. my cancer genome https://www. mycancergenome.org/content/disease/lung-cancer/pik3ca/8/ (Updated January 13), 2017.

37. Fiala O, Pesek M, Finek J, Benesova L, Belsanova B and Minarik M: The dominant role of G12C over other KRAS mutation types in the negative prediction of efficacy of epidermal growth factor receptor tyrosine kinase inhibitors in non-small cell lung cancer. Cancer Genet 206: 26-31, 2013.
38. Riely GJ and Ladanyi M: KRAS mutations: An old oncogene becomes a new predictive biomarker. J Mol Diagn 10: 493-495, 2008

39. Riely GJ, Marks J and Pao W: KRAS mutations in non-small cell lung cancer. Proc Am Thorac Soc 6: 201-205, 2009.

40. Bhattacharya S, Socinski MA and Burns TF: KRAS mutant lung cancer: Progress thus far on an elusive therapeutic target. Clin Transl Med 4: 35, 2015.

41. JännePA, Shaw AT,Pereira JR, Jeannin G, Vansteenkiste J, Barrios C Franke FA, Grinsted L, Zazulina V, Smith P, et al: Selumetinib plus docetaxel for KRAS-mutant advanced non-small-cell lung cancer: A randomised, multicentre, placebo-controlled, phase 2 study. Lancet Oncol 14: 38-47, 2013.

42. Carretero J, Shimamura T, Rikova K, Jackson AL, Wilkerson MD, Borgman CL, Buttarazzi MS, Sanofsky BA, McNamara KL, Brandstetter KA, et al: Integrative genomic and proteomic analyses identify targets for Lkb1-deficient metastatic lung tumors. Cancer Cell 17: 547-559, 2010.

43. Chen Z, Cheng K, Walton Z, Wang Y, Ebi H, Shimamura T, Liu Y, Tupper T, Ouyang J, Li J, et al: A murine lung cancer co-clinical trial identifies genetic modifiers of therapeutic response. Nature 483: 613-617, 2012

44. Infante JR,Fecher LA, Falchook GS, Nallapareddy S, Gordon MS, Becerra C, DeMarini DJ, Cox DS, Xu Y, Morris SR, et al: Safety, pharmacokinetic, pharmacodynamic, and efficacy data for the oral MEK inhibitor trametinib: a phase 1 dose-escalation trial. Lancet Oncol 13: 773-781, 2012.

45. Xing X, Cai W, Shi H, Wang Y, Li M, Jiao J and Chen M: The prognostic value of CDKN2A hypermethylation in colorectal cancer: A meta-analysis. Br J Cancer 108: 2542-2548, 2013.

46. Padhi SS, Roy S, Kar M, Saha A, Roy S, Adhya A, Baisakh M and Banerjee B: Role of CDKN2A/p16 expression in the prognostication of oral squamous cell carcinoma. Oral Oncol 73: 27-35, 2017.

47. Kim N, Song M, Kim S, Seo Y, Kim Y and Yoon S: Differential regulation and synthetic lethality of exclusive RB1 and CDKN2A mutations in lung cancer. Int J Oncol 48: 367-375, 2016.

48. Gopalan PK, Pinder MC, Chiappori A, Ivey AM, Villegas AG and Kaye FJ: A phase II clinical trial of the CDK4/6 inhibitor palbociclib (PD0332991) in previously treated, advanced non-small cell lung cancer (NSCLC) patients with inactivated CDKN2A. J Clin Oncol 32: 8077, 2014.

49. Logan JE, Mostofizadeh N, Desai AJ, VON Euw E, Conklin D, Konkankit V, Hamidi H, Eckardt M, Anderson L, Chen HW, et al: PD-0332991, a potent and selective inhibitor of cyclin-dependent kinase $4 / 6$, demonstrates inhibition of proliferation in renal cell carcinoma at nanomolar concentrations and molecular markers predict for sensitivity. Anticancer Res 33: 2997-3004, 2013.

50. Young RJ, Waldeck K, Martin C, Foo JH, Cameron DP, Kirby L, Do H, Mitchell C, Cullinane C, Liu W, et al: Loss of CDKN2A expression is a frequent event in primary invasive melanoma and correlates with sensitivity to the CDK4/6 inhibitor PD0332991 in melanoma cell lines. Pigment Cell Melanoma Res 27: 590-600, 2014.

51. Konecny GE, Winterhoff B, Kolarova T, Qi J, Manivong K, Dering J, Yang G, Chalukya M, Wang HJ, Anderson L, et al: Expression of p16 and retinoblastoma determines response to CDK4/6 inhibition in ovarian cancer. Clin Cancer Res 17: 1591-1602, 2011.

52. Finn RS, Dering J, Conklin D, Kalous O, Cohen DJ, Desai AJ, Ginther C, Atefi M, Chen I, Fowst C, et al: PD 0332991, a selective cyclin D kinase 4/6 inhibitor, preferentially inhibits proliferation of luminal estrogen receptor-positive human breast cancer cell lines in vitro. Breast Cancer Res 11: R77, 2009.

53. Kanwal M, Ding XJ and Cao Y: Familial risk for lung cancer. Oncol Lett 13: 535-542, 2017.

This work is licensed under a Creative Commons Attribution-NonCommercial-NoDerivatives 4.0 International (CC BY-NC-ND 4.0) License. 